Surprisingly, in a continent where Kakiemon porcelain has been held in the highest regard for over 300 years, this is the first European-language book dedicated solely to the subject. As the author points out, the existing literature consists largely of Japanese-language publications (often extremely hard to find) or wider-ranging scholarly monographs in European languages that include sections on Kakiemon. This attractive book, elegantly designed and with delightful attention to detail (right down to the endpapers decorated in a pattern of Kakiemon porcelain shapes), fills the gap admirably. Written as a handbook, with a lightness of touch that makes it a pleasure to use, it is a highly practical publication. Small and portable, it nevertheless manages to pack a huge amount of information (and over 300 colour illustrations) into a clear and well-organized structure. It is written in an engaging, accessible style, with the author's love of his subject shining through every page. Even the bibliography is a pleasure to read! Yet the emphasis on accessibility is not at the expense of content: the handbook provides a lucid and concise distillation of current knowledge and contributes important new information and new ideas to the field.

The first part of the book (Chapters 1-3) sets Kakiemon porcelain within its historical context. It starts with a succinct overview of the Japanese export porcelain trade from its beginnings in the 1650 s to the final years of private trade in the early 18th century. This is followed by an account of the reception of Kakiemon porcelain in Europe. This is a subject that has been extensively documented, yet the Handbook sheds fresh light on the specific role of Kakiemon within royal interiors of the late 17 th century, and later as top-end special orders and as coveted collectors' items (as illustrated by the fascinating collection at Twickel). What becomes clear is just how briefly Kakiemon was exported from Japan: as early as 1695 there was a shift in taste away from Kakiemon towards the Imari style. The introductory chapters conclude with a valuable section on Kakiemon porcelain for the domestic Japanese market. This is an area that is largely neglected in European writing.

The second half of the book (Chapters 4-6) focuses on the objects themselves, beginning with a chronological overview of the characteristics and changing styles of Kakiemon porcelain, right up to the present day and the work of the current Kakiemon XIV. This survey, which makes effective use of datable pieces, will be particularly useful in providing tools for the dating, attribution and evaluation of Kakiemon porcelain. Menno Fitski also proposes a new classification of Kakiemon, based entirely on the site of production. Thus he distinguishes between 'Kakiemon' and 'Kakiemon-style' porcelain, depending simply on whether pieces were made at the N Nangawara $_{55 \mathrm{Am}}$ or Uchiyama kilns. Further chapters describe manufacturing processes and access 
common Kakiemon designs and motifs. It is surprising how laborious it can be to track down this sort of information - how useful to have it all in one place! Another feature that appealed to me was the use of highlighted grey boxes containing nuggets of useful information, such as the location of important collections of Kakiemon porcelain, or the physical characteristics of different porcelain types.

The author has chosen not to use footnotes, a decision which certainly contributes to the accessible, uncluttered style of the book. On several occasions, I found myself wanting to know more about sources than was provided in the sources chapter (with literature references listed, footnotestyle, as they relate to specific chapters). However, this is hardly a cause for complaint when the author includes in his introduction the friendliest of invitations to contact him personally for any additional references.

At $€ 69.50$, the Handbook is not cheap, but this reviewer believes that it is worth every cent. It will be invaluable to collectors, art historians and museum professionals alike.

- Dr Clare Pollard is Curator of Japanese Art at the Ashmolean Museum. She previously worked at the Chester Beatty Library, Dublin, and the Art Gallery of New South Wales, Sydney. Her research has mainly focused on Miyagawa Kozan and Meiji ceramics.



- Menno Fitski, Kakiemon Porcelain: A Handbook, Leiden University Press-Rijksmuseum, Leiden-Amsterdam, 2011, paperback, 176 pp., over 300 colour ills., ISBN 978-908-72-8126-7, € 69.50 


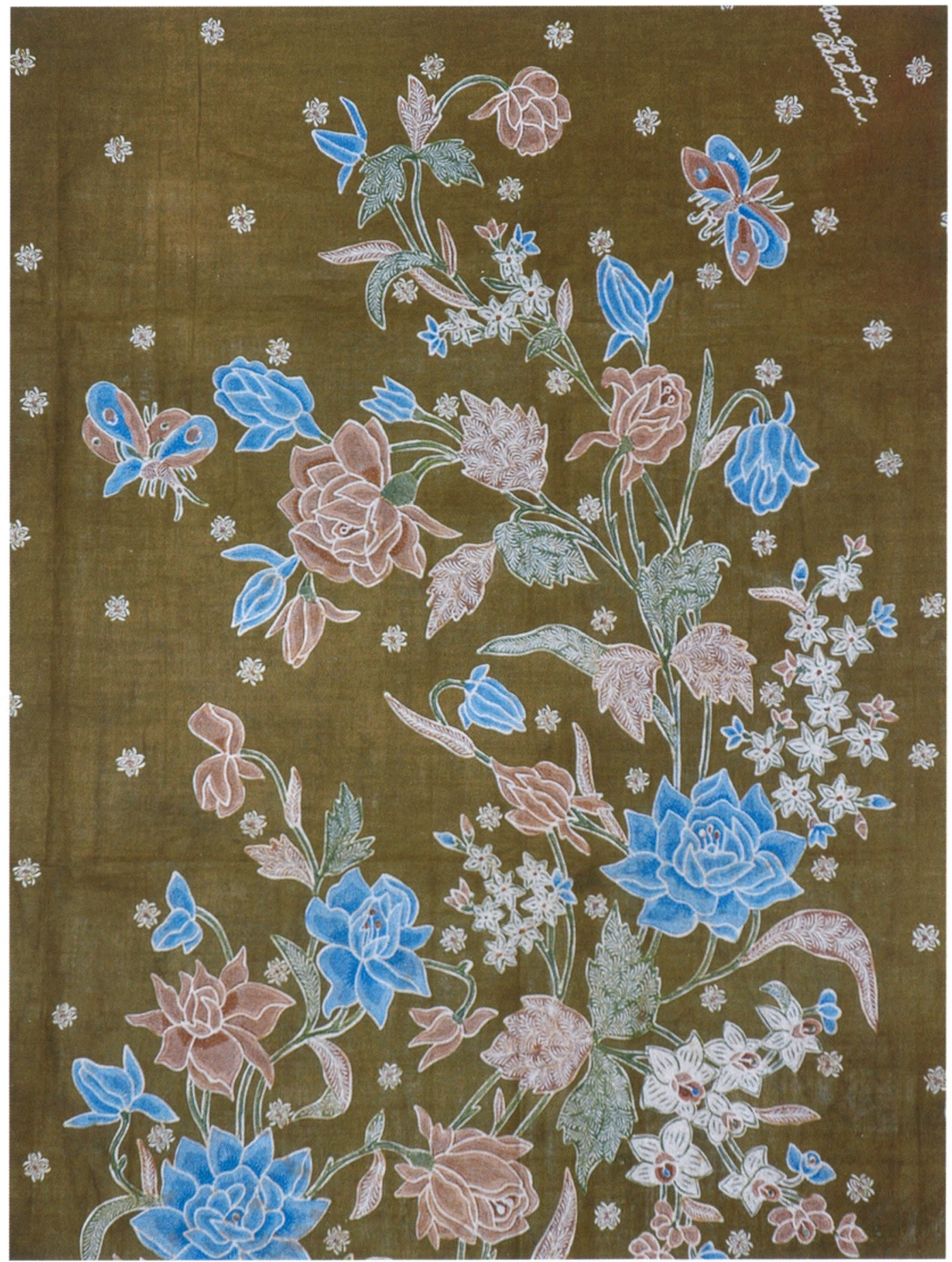

\section{Een detail van een van}

